\title{
Study of Vessel Oil Spill Damage Evaluating Model Based on the ANFIS
}

\author{
Yuanyuan $\mathrm{Li}^{*}$ \\ Department of Maritime and Transportation \\ Ningbo University \\ Ningbo, 315211, China
}

\author{
Pengjun Zheng \\ Department of Maritime and Transportation \\ Ningbo University \\ Ningbo, 315211, China
}

\begin{abstract}
Considering the randomness and complexity of vessel oil spill accidents, the oil spill quantity, clean-up response, the oil spill area and the environment sensitivity were taken as the influencing factors through the analytic hierarchy process. Based on the study of the Adaptive Neural Fuzzy Inference System(ANFIS), a nonlinear fuzzy model to evaluate oil spill damage was established. Combined with the oil spill data assembled by the International Oil Pollution Compensation Fund (IOPCF), the model simulation and prediction for vessel oil spill damage has been made. The fact validates the feasibility of the ANFIS evaluating model in vessel oil spill compensation.
\end{abstract}

Keywords-vessel oil spill; the adaptive neural fuzzy inference system; damage assessment; model simulation

\section{INTRODUCTION}

With the level of the marine environment protection enhancing in recent years, the number of oil spills in the seas have decreased, which we can see from the data derived from the International Tanker Owners Pollution Federation (ITOPF), which has built a database with the number of oil spills of 7 tonnes or more from 1970 to 2014. However, it is still necessary to analyse deeply how the damage associates with oil spills behave.

Numerous studies have been carried out on oil spill cost estimations[1-4]. At present, the assessment of the damage of marine oil spill accident come in two types: direct statistical method and indirect assessment method at home and abroad. Although the former seems to be intuitive and comprehensive, the assessment process is always tedious and less efficient, which goes against the implementation of oil spill emergency plan later. On the other hand, due to the complexity of the oil spill factors[5], the traditional regression and interpolation methods can not solve the nonlinear relationship of small sample events well. Therefore, this paper mainly focuses on the following issues: Firstly, the quantitative analysis of the factors affecting the oil spill damage is provided; Then, to reflect the relationship between oil spill influencing factors and oil spill damage by machine autonomous learning, the ANFIS model is established. With the training results and verification analysis, this paper proposes an effective and scientific method for evaluating oil spill damage in vessels, which has extremely important significance to improve the efficiency of oil spill removal and the effect of environmental restoration.

\section{METHODS}

\section{A. The Analytic Hierarchy Process}

It is essential to screen the influencing factors of damage before the prediction of oil spill damage compensation with the model. Too few factors will affect the accuracy of the prediction while too many factors may cause the model to fall into local optimization problem, which is difficult to get the global optimization solution. As an effective decision analysis device with mathematical method, the analytic hierarchy process(AHP)[6], is widely applied to analyse complex decisions containing many criteria[7].In AHP, criteria weights and pairwise comparisons always depend on calculations of a generated matrix, and the result above may also affect the consistency ratio $(\mathrm{CR})$ of decisions, which reveals the random probability of values. Because of its high degree of systematic and flexible features, the AHP can apply to solve factor screening problem properly.

\section{B. The Adaptive Neural Fuzzy Inference System}

The Adaptive Neural Fuzzy Inference System (ANFIS)[810] has the adaptive and non-adaptive nodes as an adaptive network and its function is equivalent to a fuzzy inference system. ANFIS parameters are adjusted by using a backward propagation gradient descent with a given input data set and a least squares type of a given output data set. The ANFIS system has better advantage than traditional regression model in cases which have no definitive relationship between the input and output variables, since the relationship is properly established through the self-learning process[11]. Therefore, some complex non-linear problems such as the damage of vessel oil spill can be dealt with the ANFIS model.

\section{MODEL CONSTRUCTION}

\section{A. Selection of Fuzzy Variable}

1) Variable selection. Based on the principle of hierarchy, importance, protection and exploitation, the weight values of each evaluation factor were determined by the AHP and the questionnaire and then the variables factors were selected. There were 40 questionnaires and 30 actual recovery with masters, including the classification society management personnel, the port authority, the professors, other personnel, etc, which achieves a $75 \%$ recovery rate. First of all, the AHP needs to establish the structure of vessel oil spill assessment index system[12]. Its target layer $\mathrm{A}$ is the comprehensive 
assessment of damage degree for marine oil spill accident and $\mathrm{B}$ is the primary indicator layer, including oil spillage, oil spill type, marine conditions, clean-up response, environmental sensitivity and vessel status, $\mathrm{C}$ is the secondary indicator layer with 16 evaluation factors.

The key steps based on the idea of AHP are listed as follows[13]:

1) Construct the judgment matrix;

2) Rank the importance of the factors in this level in contrast with the upper layer of a factor and to get the consistency check of judgment matrix;

3) Rank weights for the relative importance of a certain level of all factors to the total target.

Notably, to determine the extent to which an inconsistency is allowed, CR should be calculated, that is,

$$
C R=\frac{C I}{R I}
$$

where RI is defined as the random consistency index and CI is the consistency index , which means the greater value, the more serious the degree of consistency. If $\mathrm{CR}<=0.10$, there are satisfactory inconsistencies. If $\mathrm{CR}>0.10$, the degree of consistency is unusable. In this case, the result of CR is as follows:

$$
\begin{aligned}
& C I=\sum_{i=1}^{n} a_{i}(C I) \\
& =0.0371 \times 0.00+0.049 \times 0.014 \\
& +0.332 \times 0.001+0.098 \times 0.00 \\
& +0.084 \times 0.071+0.066 \times 0.034 \\
& =0.009 \\
& R I=\sum_{i=1}^{n} a_{i}(R I) \\
& =0.0371 \times 0.00+0.049 \times 0.52 \\
& +0.332 \times 0.52+0.098 \times 0.00 \\
& +0.084 \times 1.26+0.066 \times 0.89 \\
& =0.3627 \\
& C R=\frac{C I}{R I}=\frac{0.009}{0.3627}=0.0248<0.1
\end{aligned}
$$

Therefore, the results of AHP is satisfactory. Through the analysis of the results, we notice that the B layer index is the direct influence factor of the oil spill damage assessment and its weight value sort order is about oil spillage( 0.371$)$, oil spill type(0.049), marine conditions(0.332), environmental sensitivity(0.098), clean-up response(0.084), ship status(0.066), respectively. That indicates that the impact of oil spillage on the damage of oil spill is the biggest, and the marine conditions is the key factor with higher weight. Environmental sensitivity often involves environmental protection, which is one of the three major factors. Although the pollution situation factor is also important, the actual data acquisition is rarely available. Given the results of the above analysis and the characteristics of the sudden and complexity of vessel oil spill, this paper screens oil spillage, clean-up response, marine conditions and environmental sensitivity as the ANFIS model variables.

2) Data processing. In order to gather data for the model, literature survey and expert knowledge are extensively utilized and the oil spill data of the International Oil Pollution Compensation Fund (IOPCF) are provided as a reference. Firstly, 50 groups data were chosen as a preliminary choice, then the correlation analysis was used for excluding the possible abnormal data. Finally, as we can see from the Figure 1 , only 41 data were determined because of the $73 \%$ correlation between the oil spillage and compensation account.

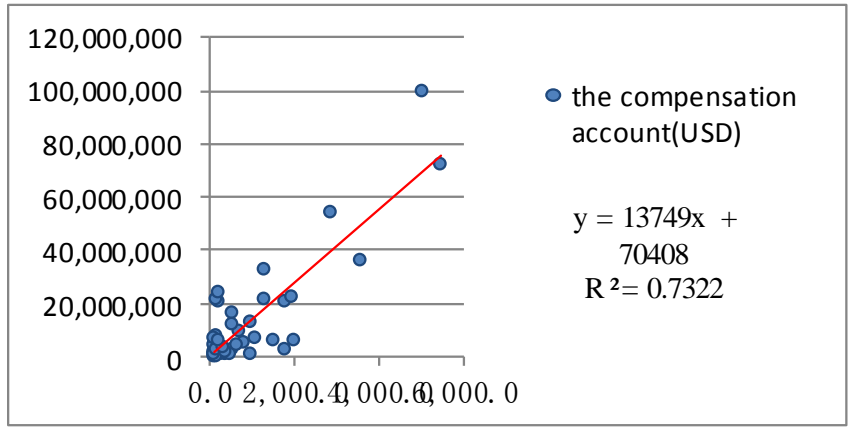

FIGURE I. THE TESTING RESULTS OF THE MODEL

Therefore, the more in-depth analysis was done with those 41 data, in which 35 data sets were used for training, and 6 data sets for testing. The data of Min-max standardization method is adopted for the variables of oil spillage and compensation amount. Before that, the cost has been converted to US Dollars taking care to the time of accident happened and then capitalized into 2013 US Dollars .The fuzzy mathematics evaluation method is used for the variable of marine conditions and the quantitative of data is realized by setting up factor set, comment set and making comprehensive evaluation[14]. By means of checking correlation coefficient form, the environmental sensitivity variable is determined. Finally, the concrete data preprocessing is accomplished with Excel and Matlab programming eventually. Finally, the normalized data are shown in Table 1. 
TABLE I. THE NORMALIZED DATA OF OIL SPILL ACCIDENTS

\begin{tabular}{|c|c|c|c|c|c|}
\hline \multirow{2}{*}{$\begin{array}{c}\text { Case } \\
\text { Number }\end{array}$} & \multicolumn{4}{|c|}{ The input variables } & \multirow{2}{*}{$\begin{array}{c}\text { The output } \\
\text { variable }\end{array}$} \\
\hline & $X 1$ & $X 2$ & $X 3$ & $X 4$ & \\
\hline 1 & 0.221 & 0.493 & 0.580 & 0.350 & 0.3271 \\
\hline 2 & 0.022 & 0.332 & 0.130 & 0.410 & 0.2377 \\
\hline 3 & 0.089 & 0.452 & 0.271 & 0.262 & 0.1193 \\
\hline 4 & 0.914 & 0.280 & 0.455 & 0.426 & 1.0000 \\
\hline 5 & 0.003 & 0.057 & 0.529 & 0.412 & 0.0625 \\
\hline 6 & 0.520 & 0.393 & 0.565 & 0.738 & 0.5404 \\
\hline 7 & 0.317 & 0.055 & 0.183 & 0.196 & 0.2030 \\
\hline 8 & 0.649 & 0.529 & 0.272 & 0.429 & 0.3574 \\
\hline 9 & 0.008 & 0.024 & 0.196 & 0.082 & 0.0048 \\
\hline 10 & 0.345 & 0.623 & 0.402 & 0.240 & 0.2194 \\
\hline 11 & 0.013 & 0.610 & 0.240 & 0.179 & 0.0212 \\
\hline 12 & 0.059 & 0.210 & 0.455 & 0.358 & 0.0186 \\
\hline 13 & 0.102 & 0.520 & 0.358 & 0.172 & 0.0387 \\
\hline 14 & 0.262 & 0.238 & 0.417 & 0.800 & 0.0573 \\
\hline 15 & 0.041 & 0.605 & 0.263 & 0.258 & 0.0315 \\
\hline 16 & 0.225 & 0.576 & 0.486 & 0.428 & 0.2137 \\
\hline 17 & 0.024 & 0.457 & 0.203 & 0.665 & 0.0596 \\
\hline 18 & 0.041 & 0.324 & 0.464 & 0.366 & 0.0215 \\
\hline 19 & 0.022 & 0.115 & 0.607 & 0.699 & 0.0336 \\
\hline 20 & 0.018 & 0.429 & 0.551 & 0.726 & 0.0766 \\
\hline 21 & 0.1144 & 0.3801 & 0.5942 & 0.2015 & 0.0925 \\
\hline 22 & 0.1698 & 0.3635 & 0.1202 & 0.3448 & 0.0072 \\
\hline 23 & 0.3542 & 0.6070 & 0.2530 & 0.8597 & 0.0581 \\
\hline 24 & 0.1882 & 0.6652 & 0.4550 & 0.7100 & 0.0671 \\
\hline 25 & 0.0314 & 0.2945 & 0.4986 & 0.3293 & 0.0031 \\
\hline 26 & 0.1328 & 0.0526 & 0.1768 & 0.1562 & 0.0513 \\
\hline 27 & 0.0194 & 0.6076 & 0.5100 & 0.2006 & 0.2146 \\
\hline 28 & 0.0055 & 0.3269 & 0.1430 & 0.0879 & 0.0085 \\
\hline 29 & 0.32023 & 0.5731 & 0.2547 & 0.1894 & 0.0239 \\
\hline 30 & 0.0111 & 0.0403 & 0.5011 & 0.2593 & 0.0000 \\
\hline 31 & 0.0000 & 0.0357 & 0.1005 & 0.1085 & 0.0010 \\
\hline 32 & 0.0812 & 0.0797 & 0.1613 & 0.1859 & 0.1633 \\
\hline 33 & 0.0775 & 0.4419 & 0.5866 & 0.6004 & 0.0039 \\
\hline 34 & 1.0000 & 0.3962 & 0.4001 & 0.4310 & 0.7217 \\
\hline 35 & 0.0849 & 0.3818 & 0.5173 & 0.6038 & 0.0248 \\
\hline 36 & 0.0037 & 0.2926 & 0.5802 & 0.6578 & 0.0125 \\
\hline 37 & 0.0351 & 0.3446 & 0.4184 & 0.3952 & 0.0290 \\
\hline 38 & 0.1697 & 0.3508 & 0.4603 & 0.3419 & 0.1231 \\
\hline 39 & 0.0227 & 0.0989 & 0.1403 & 0.2555 & 0.2012 \\
\hline 40 & 0.0009 & 0.0348 & 0.2773 & 0.1963 & 0.0362 \\
\hline 41 & 0.0511 & 0.6451 & 0.5598 & 0.5988 & 0.0048 \\
\hline
\end{tabular}

B. Establishment of the Model

This paper selects oil spillage (X1), marine conditions (X2), clean-up response(X3), environmental sensitivity (X4) as the input variables and the compensation account (Y1) as the output variable. 2 membership functions of "trimf" are given for each input variable while the output function type is "constant" function. The learning method puts to use the hybrid learning algorithm with 100 training times. The construction of the oil spill damage model on ANFIS is divided into the following steps [15]:

1) Generate the training data and inspection data;

2) Ensure the type and number of membership functions for variables;

3) Create the initial FIS structure by genfis 1 function;

4) Set the ANFIS training parameters and make the ANFIS function training;
5) Detect the performance of the FIS.

\section{RESULTS AND DISCUSSION}

The training results of the model with Matlab programming are shown in Figure 2. It can be seen the output data of the system fits well with the original training data with high accuracy and the root mean square error (RMSE) is 0.0319, which indicates to meet the system requirements.

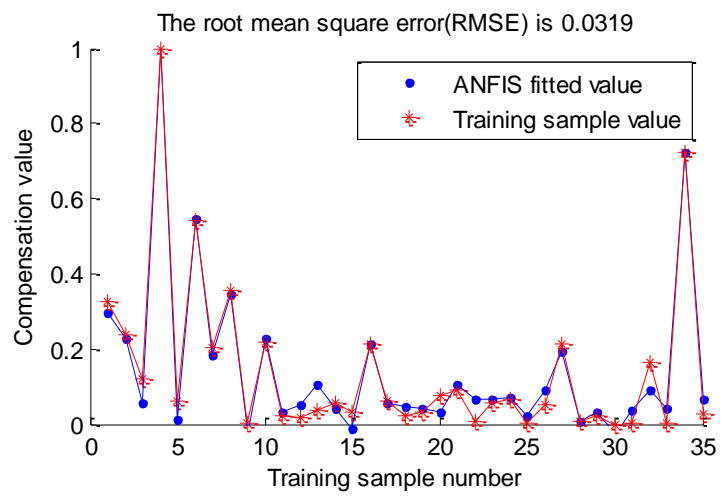

FIGURE II. THE TRAINING RESULTS OF THE MODEL

The distributions of differences between ANFIS predictive values and their actual values are shown in Figure III and the root mean square error (RMSE) is 0.0330 . In order to evaluate the accuracy of ANFIS model predictions further, in this study, the predictive values are normalized by range formula, in which the result is shown in Table 2.

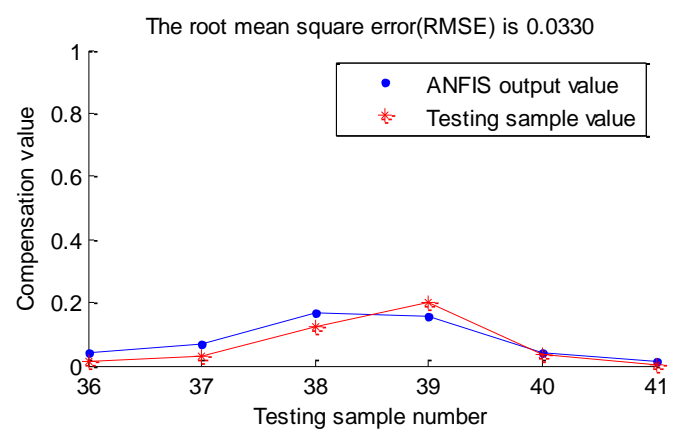

FIGURE III. THE TESTING RESULTS OF THE MODEL

TABLE II. THE CONTRAST RESULT OF THE ACTUAL AND THE FORECAST VALUES

\begin{tabular}{|l|l|l|l|l|}
\hline $\begin{array}{l}\text { Case } \\
\text { Numb } \\
\text { er }\end{array}$ & $\begin{array}{l}\text { Normalized } \\
\text { interval value }\end{array}$ & $\begin{array}{l}\text { Anti normalized } \\
\text { monetary value }\end{array}$ \\
\cline { 2 - 5 } & $\begin{array}{l}\text { Actual } \\
\text { value }\end{array}$ & $\begin{array}{l}\text { Predictive } \\
\text { value }\end{array}$ & $\begin{array}{l}\text { Actual } \\
\text { value } \text { (\$) }\end{array}$ & $\begin{array}{l}\text { Predictive } \\
\text { value } \text { (\$) }\end{array}$ \\
\hline 36 & 0.0125 & 0.0387 & $1,397,418$ & $4,002,283$ \\
\hline 37 & 0.0290 & 0.0679 & $3,035,103$ & $6,905,779$ \\
\hline 38 & 0.1231 & 0.1682 & $12,391,861$ & $16,879,089$ \\
\hline 39 & 0.2012 & 0.1539 & $20,156,495$ & $15,457,171$ \\
\hline 40 & 0.0362 & 0.0402 & $3,752,214$ & $4,151,435$ \\
\hline 41 & 0.0048 & 0.0123 & 634,373 & $1,377,204$ \\
\hline
\end{tabular}

As we can see from the table, it seems that the relative error of the six samples is much larger than general precision prediction, which even comes out four times bigger than the sample value. However, considering the complexity of reality in oil spill accidents, the actual payment capacity of the 
indemnitor and a certain degree of discretionary power of the judge, the estimate of compensation account is much better seen as 'orders of magnitude' rather than precise figures. Therefore, the errors of the five test samples are within an acceptable range and the ANFIS model can predict the damage of vessel oil spill as a fast and effective method for the evaluation, which can be used for reference in dealing with quantify roughly losses of oil spill accidents.

\section{CONCLUSIONS}

In conclusion, the damage of vessel oil spill was studied by combining the analytic hierarchy process (AHP) and the adaptive neural fuzzy inference system (ANFIS) in this paper. The main factors affecting the oil spill damage are determined by the AHP, which includes oil spillage, clean-up response, marine conditions and environmental sensitivity. Then the ANFIS model is established and tested based on the data of the International Oil Pollution Compensation Fund (IOPCF). Results are showed with higher training accuracy and better forecast effect in an acceptable range. Therefore, the feasibility of the ANFIS assessment model in the assessment of the oil spill damage is verified. And it is hoped that these analyses can be further beneficial in dealing with the accident loss for the maritime oil spill and decision department.

\section{ACKNOWLEDGMENT}

I am deeply indebted to a number of people without whose encouragement and assistance this thesis would not have been completed.

I am profoundly grateful to my supervisor, Pengjun Zheng, whose illuminating instruction and expert advice have guided me through every step of my writing of this thesis. He gave me lots of inspirations and encouragement, which tempt me to keep going on. He read every word of every draft, pointing out the mistakes and helping me to clarify my ideas. His broad and profound knowledge gave me great impression as well as great help.

Meanwhile, my great gratitude goes to many of my friends and classmates and with the selfless and generously help of them, I can appreciate the strength of the team deeply, which makes us go much further.

\section{REFERENCES}

[1] Kontovas Christos A,Psaraftis Harilaos N,Ventikos Nikolaos P, "An empirical analysis of IOPCF oil spill cost data," Marine Pollution Bulletin, vol.60 (9), pp.1455-1466,2010.

[2] Deborah French McCay, "Development and application of damage assessment modeling: example assessment for the North Cape oil spill," Marine Pollution Bulletin, vol.47 (9), pp.341-359, 2003.

[3] Maria Alló,Maria L. Loureiro, "Estimating a meta-damage regression model for large accidental oil spills," Ecological Economics, vol.86 , pp.167-175, 2013.

[4] Mohammad Shahriari,Anton Frost, "Oil spill cleanup cost estimationDeveloping a mathematical model for marine environment," Process Safety and Environment Protection, vol.86 (3), pp.189-197, 2008.

[5] M. El-Fadel,R. Abdallah,G, Rachid, "A modeling approach toward oil spill management along the Eastern Mediterranean," Journal of Environmental Management, vol.113, pp.93-102, 2012.

[6] Omkarprasad S. Vaidya,Sushil Kumar, "Analytic hierarchy process: An overview of applications," European Journal of Operational Research, vol.169 (1), pp.1-29, 2004.
[7] Mikko Kurttila,Mauno Pesonen,Jyrki Kangas,Miika Kajanus, "Utilizing the analytic hierarchy process (AHP) in SWOT analysis - a hybrid method and its application to a forest-certification case," Forest Policy and Economics,vol.1 (1), pp.41-52, 2000.

[8] L. Yang,E. Entchev, "Performance prediction of a hybrid microgeneration system using Adaptive Neuro-Fuzzy Inference System (ANFIS) technique," Applied Energy, vol.134, pp.197-203,2014.

[9] Swasti R. Khuntia,Sidhartha Pand, "ANFIS approach for SSSC controller design for the improvement of transient stability performance," Mathematical and Computer Modelling, vol.57, pp. 289-300, 2013.

[10] Leila Naderloo,Reza Alimardani,Mahmoud Omid et.al, "Application of ANFIS to predict crop yield based on different energy inputs," Measurement, vol.45 (6), pp.1406-1413, 2012.

[11] Ilija Svalina,Vjekoslav Galzina,Roberto Lujić,Goran Šimunović, "An adaptive network-based fuzzy inference system (ANFIS) for the forecasting: The case of close price indices," Expert Systems With Applications, vol.40 (15), pp.6055-6063, 2013.

[12] Tayfun Cay,Mevlut Uyan, "Evaluation of reallocation criteria in land consolidation studies using the Analytic Hierarchy Process (AHP)," Land Use Policy, vol.30 (1), pp.541-548, 2013.

[13] Zeki Ayağ,R. G. Özdemir, "A Fuzzy AHP Approach to Evaluating Machine Tool Alternatives," Journal of Intelligent Manufacturing, vol.17 (2), pp.179-190, 2006.

[14] Libor Běhounek,Petr Cintula., "From fuzzy logic to fuzzy mathematics: A methodological manifesto," Fuzzy Sets and Systems, vol.157 (5), pp.642-646, 2005.

[15] Mansour Zare,Jalil Vahdati Khaki, “ Prediction of mechanical properties of a warm compacted molybdenum prealloy using artificial neural network and adaptive neuro-fuzzy models," Materials and Design, vol.38, pp. 26-31, 2012. 